\title{
TOURISM DISCOURSE: STRATEGIES AND DIFFICULTIES IN TRANSLATING HOTEL WEBSITES ${ }^{1}$
}

\author{
Svetlana A. Korolkova \\ Volgograd State University, Volgograd, Russian Federation \\ Anna A. Novozhilova \\ Volgograd State University, Volgograd, Russian Federation \\ Anastasiya M. Sheyko \\ Volgograd State University, Volgograd, Russian Federation
}

\begin{abstract}
The article presents an analysis of one of the most dynamically growing spheres of translation translation in tourism, namely localization of hotel websites. Undoubtedly, the Internet is the main source of information retrieval and a tool enhancing tourism attractiveness of a destination, which means that while translating hotel websites one should pay great attention to the language content. The analysis conducted by the authors allows concluding that most of the translations feature a lot of language mistakes: from lexical incongruity to spelling, making translated texts unreadable and not corresponding to their communicative and pragmatic functions. If a translator holds a basic strategy of producing a new text using peculiar stylistic markers and figurative language, characterizing other linguistic culture, and sometimes changes the form and structure of the text in the source language, then the translated text functions as an element, attracting new customers.

This situation reflects the existence of highly widespread problems, found in the sphere of translation: the growing number of people speaking foreign languages makes professional competences of translators worthless. Together with the expansion of Machine Translation it lowers the quality of a "ready" product - localized text making recipients and senders to perceive the inferior language content as normal.

Key words: translation, tourism, attractiveness, website localization, pragmatic adaptation, linguistic culture, professional competence, language norm.

Citation. Korolkova S.A., Novozhilova A.A., Sheyko A.M. Tourism Discourse: Strategies and Difficulties in Translating Hotel Websites. Vestnik Volgogradskogo gosudarstvennogo universiteta. Seriya 2, Yazykoznanie [Science Journal of Volgograd State University. Linguistics], 2017, vol. 16, no. 3, pp. 80-89. (in Russian). DOI: $\sum$ https://doi.org/10.15688/jvolsu2.2017.3.8

\section{ТУРИСТИЧЕСКИЙ ДИСКУРС: СТРАТЕГИИ И ПРОБЛЕМЫ ПЕРЕВОДА САЙТОВ ОТЕЛЕЙ ${ }^{1}$}

\section{Светлана Азадовна Королькова}

Волгоградский государственный университет, г. Волгоград, Российская Федерация

Анна Алексеевна Новожилова

Волгоградский государственный университет, г. Волгоград, Российская Федерация

Анастасия Михайловна Шейко

Волгоградский государственный университет, г. Волгоград, Российская Федерация 
Аннотация. Статья посвящена анализу одного из динамичных направлений переводческого бизнеса переводу в туристической отрасли, а именно письменному переводу сайтов отеля с русского языка на английский и с английского языка на русский. Доказано, что, поскольку интернет является основным источником информации и инструментом формирования туристической аттрактивности, большое внимание в переводе следует уделять языковой составляющей контента гостиничных сайтов. В результате лингвистического анализа установлено, что независимо от направления перевода значительное количество переводов характеризуется нарушением лексических, грамматических, орфографических и пунктуационных норм, что делает текст нечитабельным, не соответствующим своей коммуникативно-прагматической функции. В качестве причин снижения качества переводного контента авторы называют обесценивание труда профессионального переводчика, которому способствуют увеличение количества людей, знающих иностранные языки, и некомпетентное использование ими машинного перевода. Установлено, что переводной текст выполняет свою основную функцию, привлекая потенциальных клиентов, в случае, если профессиональный переводчик придерживается стратегии порождения нового текста с определенными стилистическими маркерами и образными характеристиками, соответствующими иной лингвокультуре, и изменяет форму и структуру оригинального текста.

Ключевые слова: перевод, туристическая отрасль, аттрактивность, локализация сайта, прагматическая адаптация, лингвокультура, профессиональная компетенция, языковая норма.

Цитирование. Королькова С. А., Новожилова А. А., Шейко А. М. Туристический дискурс: стратегии и проблемы перевода сайтов отелей // Вестник Волгоградского государственного университета. Серия 2, Языкознание. - 2017. - Т. 16, № 3. - C. 80-89. - DOI: https://doi.org/10.15688/jvolsu2.2017.3.8

1

На процессы взаимодействия и сближения различных культур и наций большое влияние оказывает туристическая отрасль. Туризм, «несмотря на череду экономических кризисов и сложную военно-политическую обстановку, по-прежнему демонстрирует неофициальный статус “мирового феномена"» [Дорофеева, Дорофеев, 2015, с. 80]. В.А. Митягина справедливо утверждает, что развитие этой области сегодня становится «одним из проявлений готовности этносоциумов не только к диалогу и интеграции, но и к глобализации, потому что в туристической деятельности находит выражение одобрение сосуществования культур в индивидуальном опыте» [Митягина, 2009, с. 88]. По замечанию Э.Ю. Новиковой, туристическая сфера один из эффективных инструментов взаимопонимания представителей различных лингвокультур, активизации деловой и культурноопосредованной коммуникации [Новикова, 2015 , с. 53].

В настоящее время во всех сегментах туристической отрасли отмечается стремительное увеличение потоков информации, способствующее развитию международного туризма и повышающее аттрактивность различных регионов среди зарубежных туристов; весьма востребованным становится также представление информационно-рекламных материалов, к которым относится большинство текстов туристического дискурса, в многоязычном формате.

Лингвистические характеристики и особенности перевода в туристическом дискурсе в последние годы активно изучаются отечественными и зарубежными лингвистами (см., например: [Меньшикова, 2010; Тарнаева, Дацюк, 2013; Dörnyei, 2005; Potočnik Topler, 2015]). Проведение таких исследований представляется актуальным, поскольку результаты лингвистического анализа многоязычных туристических ресурсов могут быть учтены их составителями и разработчиками, что будет способствовать, как показано А.А. Гуреевой, повышению качества языкового выражения информации о той или иной туристической услуге, объекте, городе и т. п. и приведет к их большей популярности среди туристов и потому к увеличению экономической прибыли [Гуреева, $2017]$.

Сказанное определяет актуальность и данной статьи. Она посвящена осмыслению транслатологических проблем, обнаруженных в результате анализа переводов материалов гостиничных сайтов в языковой паре английский - русский, и выявлению эффективных переводческих стратегий. 
2

Очевидно, что все большее число путешественников использует интернет в качестве основного средства, позволяющего изучить регионы, достопримечательности и туристическую инфраструктуру страны, которую планируется посетить. Важную роль при подготовке путешествия играет выбор гостиницы. Осуществляя его, потенциальный гость обращается к информации, размещенной на сайтах различных отелей. По этой причине она должна быть одновременно максимально лаконичной, содержательной и привлекательной. Однако наличие технически безупречного сайта с ярким дизайном и большим объемом полезной информации не является залогом того, что именно эту гостиницу выберет потенциальный гость. Существенным становится представление контента в увлекательной языковой форме. Практика показывает, что этот факт часто не учитывается отельерами при наполнении сайта, предназначенного для зарубежных гостей, которые либо не владеют иностранным языком, либо владеют им на уровне, не позволяющем свободно воспринимать предложенную информацию. Следовательно, гостиницы теряют потенциальных посетителей лишь потому, что последние не могут прочитать или найти необходимые сведения на сайтах гостиниц.

На информационном портале «Фулборд Инфо» (http://fullboard.info/), посвященном гостиничному бизнесу, утверждается, что если гостиница не существует в поисковой сети (Google, Baidu, Яндекс, Bing или Yahoo), то она не существует вообще, и именно перевод способствует тому, что гостиница будет пользоваться спросом среди потенциальных разноязычных клиентов. Руководство гостиницы, знающее обо всех преимуществах представленности в сети, всегда обеспечивает наличие перевода сайта на несколько языков, поскольку чем больше языков локализации использовано на сайте, тем большее количество людей из разных стран мира сможет на него попасть при вводе основных поисковых запросов на родном языке. Следовательно, перевод основных разделов сайта является одним из способов расширения клиентской базы. При этом нельзя оставлять без внимания тот факт, что «при переводе текстов гостиничных сайтов действуют определенные коммуникативные и языковые нормы и прагматические установки» [Новожилова, 2015, с. 141]. Потенциальные гости, посетив сайт, на страницах которого говорится про пышную зелень, насыщенную синеву океана, живописные пейзажи и пляжи с золотым песком, по-видимому, представят это, возможно, остановят свой выбор именно на данной гостинице.

\section{3}

Перевод туристических контентов в общем и гостиничных сайтов в частности - это не механическая перекодировка информации с одного языка на другой, а ее адекватная локализация, под которой лингвисты понимают максимальную ориентированность на потенциальных получателей и прагматическую адаптацию текста к их языковым особенностям и национально-культурной специфике [Austermühl, 2015; Pym, 2011; Sandrini, 2005]. Это, прежде всего, «выделение информации, релевантной для иностранного туриста, устранение ненужных деталей и передача всей эмоциональности и экспрессивной окрашенности, свойственной текстам сайтов отелей» [Новожилова, 2016, с. 92].

Материалом для нашего исследования послужили англоязычные и русскоязычные сайты гостиниц (всего 75); их переводы взяты либо с официальных сайтов гостиниц, либо выполнены авторами статьи в рамках профессиональной деятельности. В качестве отправной точки транслатологического анализа рассмотрим перевод с английского языка на русский, который можно назвать высокопрофессиональным и образцовым с точки зрения переводческой стратегии.

\section{Текст 1 (оригинал)}

The peninsula is a true paradise full of contrasts, considered one of the most beautiful destinations on the planet. Beyond doubt it's the perfect place to go for those who wish to take back with them the most fantastic memories of an ideal Caribbean vacation, as it's one of the most pristine locations, conserving its stunning natural beauty. If you wish to enjoy a vacation surrounded by spectacular stretches of white sandy beaches and crystal-clear waters, under the 
shade of coconut palms swaying in the light breeze, it is the perfect choice. (Здесь и далее выделено нами. C. K., A. H., A. $U$.)

(http://paxnews.com/news/Tour\%20Operator/ luxury-vacations-bahia-principe-samana-experiencehappiness (дата обращения: 20.05.2017))

\section{Перевод}

Живописный полуостров - это настоящий райский уголок, наполненный чудесами. Это край контрастов, который по праву считается одним из самых интересных и красивых мест на планете. Будьте уверены, посетив этот удивительный мир и вдохнув атмосферу Карибского моря, вы увезете с собой яркие воспоминания об идеальном отпуске, проведенном в окружении нетронутой человеком бесконечно прекрасной природы. Если вы хотите насладиться роскошными песчаными пляжами с белым песком и кристально чистой водой, отдыхая в тени кокосовых пальм и ощущая нежный морской бриз, то это место создано именно для вас.

В Тексте 1 (оригинальный текст на английском языке) использовано большое количество тематически ориентированной лексики: true paradise, beautiful destinations, perfect place to go, fantastic memories, ideal vacation, pristine locations, stunning natural beauty, spectacular stretches, white sandy beaches, light breeze, perfect choice. Благодаря выбору эмотивных прилагательных и ярких сравнений переводчику удалось сохранить образность оригинального текста: живописный райский уголок, наполненный чудесами; одно из самых интересных и красивых мест на планете; удивительный мир; яркие воспоминания об идеальном отпуске; бесконечно прекрасная природа; роскошные пляжи; нежный морской бриз.

Помимо адекватного подбора эквивалентов переводчик использовал ряд трансформаций. Так, перевод словосочетания full of contrasts («полный контрастов») дан переводчиком не в первом предложении (в соответствии оригиналу), а во втором, и прилагательное full опущено; одновременно с этим в первое предложение добавлены стилистически маркированные единицы живописныгй и наполненный чудесами, компенсирующие смысл трансформированного при переводе словосочетания из исходного текста. Все это позволило нейтрализовать отрицательную коннотацию, закрепленную в русской ментально- сти, и возможность нежелательных ассоциаций. Второе предложение исходного текста разбито на два предложения в переводе, что связано с особенностями синтаксиса исходного и переводного языка. Интересное решение было найдено для перевода словосочетания ideal Caribbean vacation: за счет логического развертывания и перераспределения значений в переводе появились атмосфера Карибского моря и идеальный отпуск, что соответствует горизонту ожиданий нового получателя текста. В последнем предложении удачно использован прием прагматической замены: perfect choice в переводном тексте заменено на место создано специально для вас, что прагматически оправдано, поскольку дословный перевод прекрасный выбор недостаточно экспрессивен, в то время как предложенная переводчиком замена обеспечивает максимальное воздействие на получателя.

Переводной текст по объему несколько больше исходного текста, что обусловлено особенностями русского языка, однако он полностью отвечает всем критериям качественного перевода: отсутствуют языковые ошибки, соблюдены коммуникативные нормы, переданы прагматические установки, а именно: создать как можно более яркий образ дестинации и привлечь потенциальных посетителей. Переводческая стратегия (элиминация культурно-чуждой информации и формы при сохранении эмотивности и экспрессивности текста) реализуется с использованием ряда переводческих приемов: добавление, перераспределение значений, логическое развертывание и прагматическая адаптация. При этом большое внимание переводчиком уделено синтаксису, поскольку именно структура предложения свидетельствует о профессиональном владении грамматическими трансформациями, об умении применять их уместно и мотивировано, в соответствии с нормами русского языка.

Таким образом, выбранная переводческая стратегия - сохранение прагматической составляющей оригинального текста при конвенциональности формы текста новой лингвокультуре - обеспечивает сохранение коммуникативно-прагматической функции текста в новом лингвокультурном пространстве, а сле- 
довательно, выполняет свою «коммерческую» задачу - повысить популярность гостиницы и увеличить количество клиентов.

Анализ аналогичного по качеству перевода текста с русского языка на английский позволяет подтвердить, что независимо от направления перевода единственно верной является переводческая стратегия, нацеленная на прагматическую адаптацию содержания и трансформацию синтаксиса при сохранении эмотивной и экспрессивной составляющей.

\section{Текст 2}

Отель среднего класса для деловых поездок или отдыха

Отель 4* ... (здесь и далее название заменено многоточием. - C. K., A. H., A. $W$.) расположен в центре города на берегу Черного моря. Отдохните в любом из 200 просторных номеров (для некурящих) после работы или дня, проведенном на частном пляже отеля. Изысканный современный дизайн, вид на море или на город и исключительный сервис. Бесплатная подземная парковка для гостей. Отель ... удобно расположен в пешей доступности от аквапарка, Морского Порта, концертного зала Фестивальный, Зимнего Театра и торговых центров.

(http://www.accorhotels.com/ru/hotel-8506mercure-\%D1\%81\%D0\%BE\%D1\%87\%D0\%B8$\% \mathrm{D} 1 \% 86 \% \mathrm{D} 0 \% \mathrm{~B} 5 \% \mathrm{D} 0 \% \mathrm{BD} \% \mathrm{D} 1 \% 82 \% \mathrm{D} 1 \% 80 /$ index.shtml (дата обращения: 20.05.2017))

\section{Перевод}

(с официального сайта гостиницы)

Mid-scale hotel for business trips or leisure

The $4 *$... hotel is located in the heart of the city on the Black Sea coast. Relax in any of our 200 spacious rooms (non-smoking) after work or a day spent lounging on the hotel's own private beach. Enjoy its sophisticated contemporary design, a glorious city or sea view and our exceptional service. The ... hotel is ideally located within walking distance of the water park, sea port, concert hall, Winter Theater and various shopping facilities.

(http://www.accorhotels.com/gb/hotel-8506mercure-sochi-centre/index.shtml (дата обращения: 20.05.2017))

Прежде всего, следует отметить, что синтаксическая структура предложений в переводном тексте конвенциональна и при знакомстве с ним не вызывает отторжения. При переводе с русского языка на английский текст «персонализирован»: в перевод добавлено прилагательное our (rooms, beach), «импортиру- ющее» текст в новую лингвокультуру (значимость собственного пространства для англосаксонской культуры общеизвестна). Переводчик использует адекватные замены: в изенmpe - in the heart, торговые центры various shopping facilities, что делает текст конвенциональным, поскольку эти словосочетания ожидаемы, привычны. Переводчику удается сохранить экспрессивность текста за счет использования образных прилагательных sophisticated и exceptional. Оправдано и переводческое решение с добавлением единиц lounging и glorious: lounging «праздный, бездельничание» создает атмосферу неспешности, праздности, что полностью соответствует функции текста, glorious «великолепный, знаменитый» используется переводчиком с целью подчеркнуть для иноязычной аудитории значимость города, где расположен отель. В англоязычной версии текста отсутствует предложение Бесплатная парковка для госmей, поскольку для англофонной аудитории эта информация не является значимой, в отличие от русскоязычной аудитории: для жителя, например, какой-либо страны Западной Европы подземная стоянка является, скорее, обязательной, но не выдающейся характеристикой отеля. Таким образом, перевод текста 2 подтверждает верность выбранной переводчиком стратегии, а также адекватность и мотивированность применения переводческих приемов.

Переводы текстов 1 и 2 свидетельствуют о том, что профессиональный переводчик, хорошо понимающий стоящую перед ним задачу, имеющий сформированную операционную компетенцию, способен создать текст, который будет выполнять свою основную функцию - привлекать новых клиентов.

4

Однако большинство переводных текстов не соответствует многим предъявляемым требованиям: в них допущены языковые, речевые, прагматические и содержательные ошибки. Например, в переводе (с английского языка на русский) генерального каталога сети гостиниц премиум-класса, ориентированных на предоставление эксклюзивных услуг и привлечение самых взыскательных и требовательных посетителей, обнаружены следующие ошибки. 
Этот отель с великолепным обслуживанием само воплощение атмосферы чудесного острова с приятной температурой круглый год, в честь которого отель назван.

(http://profi.travel/uploads/ckeditor/Catalogue Bahia.pdf(дата обращения: 20.05.2017))

В высказывании нарушены синтаксические нормы русского языка, так как придаточное определительное предложение по смыслу соотносится с существительным остров, а не с существительным год, после которого оно следует. Предложение некорректно еще и потому, что в нем нарушена синтаксическая и лексическая сочетаемость. У получателя возникает отрицание текста, а соответственно, вряд ли возникнет желание воспользоваться услугами этого отеля.

...те, кто предпочитает отправиться на поиски других возможностей для развлечений, предлагаемых на острове».

(http://profi.travel/uploads/ckeditor/Catalogue Bahia.pdf(дата обращения: 20.05.2017))

Данный пример свидетельствует либо об использовании машинного перевода, либо о непрофессионализме переводчика: выделенный фрагмент - это подстрочник английской фразы с полным калькированием ее синтаксической структуры. Текст, содержащий такие ошибки, вряд ли будет создавать привлекательный образ отеля.

Нарушения различных норм современного русского языка (лексических, грамматических, орфографических, пунктуационных) отмечены во многих текстах переводов. Приведем еще несколько примеров переводов с ошибками в лексической сочетаемости и грамматическом согласовании, обусловленными калькированием исходного текста.

The exclusive is included

(http://profi.travel/uploads/ckeditor/Catalogue_

Bahia.pdf(дата обращения: 20.05.2017))

эксклюзивное включено

(предлагаемый корректный перевод: эксклюзивные удобства и услуги)

Facilities and services

(http://profi.travel/uploads/ckeditor/Catalogue

Bahia.pdf(дата обращения: 20.05.2017))

Оснащение номеров

(предлагаемый корректный перевод: услуги и удобства)
2 Студии

(http://www.mirage-hotel.ru/aboutHotel/lang/ en\#fullversion (дата обращения: 20.05.2017))

2 Studious Rooms)

(предлагаемый корректный перевод: 2 Studio

Наличие такого рода ошибок свидетельствует о том, что перевод выполняется либо не профессионалом, а «случайным» переводчиком, который, зная иностранный язык на уровне пользователя, берется за дело, которым он не владеет, либо некомпетентным переводчиком, который использует автоматический перевод («Google Переводчик», «Яндекс.Переводчик» и др.), а редактирование выполняет крайне недобросовестно. Однако и в том, и в другом случае потенциальные реципиенты получают переводы, которые не соответствуют конвенциям текста и негативно влияют на общее качество языка.

Значимой ошибкой для рекламных текстов гостиниц является незнание переводчиком стандартных формулировок, принятых для означивания одного и того же феномена в разных лингвокультурах. На переводных сайтах иностранных гостиниц встречаются такие ссылки, как более вместо подробнее и возврашение вместо назад. Адресат текста догадается, о чем идет речь, но вряд ли у него возникнет доверие к этому отелю. Получатель рекламных текстов не должен делать дополнительных интеллектуальных усилий для того, чтобы вникнуть в содержание, переданное непривычными языковыми средствами, он имеет свой горизонт ожидания, которому переводные тексты должны соответствовать. По справедливому замечанию Д. Гуадека, «перевод не сводится к простому переходу от одного языка к другому: он всегда требует полной адаптации исходного текста к иной аудитории, у которой иные привычки, иные вкусы, иной образ мысли и иное поведение. Иная аудитория должна воспринимать переводной текст так, словно он изначально создан представителем ее культуры» («En fait, la traduction ne peut pas se réduire au passage d'une langue à une autre : elle nécessite toujours une adaptation complète du document d'origine à un public qui se caractérise par des habitudes différentes, des goûts différents, des modes de pensée différents, des comportements différents. 
Un public, donc, qui devra recevoir le document traduit comme si ce dernier avait été rédigé par quelqu'un de même culture») (перевод наш. C. K., A. H., A. Ш.) [Gouadec, 1989, c. 10].

Рассмотрим текст и его перевод, не только иллюстрирующие уже выявленные нами проблемы в совокупности, но и демонстрирующие наличие еще одной проблемы (как правило, в русскоязычном интернет-пространстве) - качества исходного текста.

Текст 3 (оригинал)

\section{ПляЖНЫЙ ОТДЫХ НА МОРЕ}

Отель находится на берегу Черного моря, а ее собственный, прекрасно оборудованный, галечный пляж, рассчитан на одновременное присутствие 2000 человек.

Территория пляжа оснащена душевыми кабинами, лежаками, шезлонгами и зонтами, туалетами и кабинами для переодевания. На пляже представлен широкий выбор водных развлечений и аттракционов по приемлемым ценам: гидровелосипеды, гидроциклы, виндсерфинг, катамараны, парапланы, погружение с аквалангом. Кроме того, на пляже, установлена ротонда для выступления артистов и проведения ночных программ, есть медпункт, массажные кабинки. На пляже действует Лаунж-бар, также работают несколько ресторанов, магазинов, детский батут.

(http://www.zhem.ru/about/ (дата обращения: 20.05.2017))

\section{Перевод}

(с официального сайта гостиницы)

\section{BEACH AREA}

Well-equipped private beach has a capacity of 2000 pax. The following facilities are available: showers, sun loungers, deckchairs, parasols, restrooms and dressing rooms. The beach area is covered with authentic ocean sand for your ideal relaxation.

Enjoy water fun activities with our pedal boats, wave runners, yachts and go windsurfing, parasailing and scuba diving. Moreover there is a special stage for performances and night discos, first-aid post, brise soleil area and sports equipment rental. Several restaurants, lounge-bar, store, billiards, massage, kids trampoline are open for your convenience.

(http://www.zhem.ru/en/about/ (дата обращения: 20.05.2017))

Оригинальный текст едва ли можно назвать примером выразительной рекламы, так как, во-первых, использованные в нем прилагательные не создают в воображении потен- циального гостя заманчивых пейзажей: пляжный отдых; широкий выбор; приемлемые цены; собственный, прекрасно оборудованный, галечный пляж, рассчитан на одновременное присутствие 2000 человек. Вовторых, вместимость пляжа (2000 человек) является сомнительным преимуществом, большинство туристов, скорее, предпочли бы более уединенный отдых. В-третьих, в исходном тексте допущены пунктуационные и грамматические ошибки: лишние запятые, неверно использовано местоимение (отель находится на берегу Черного моря, а ее собственный пляж).

Перевод текста на английский язык выполнен также некачественно: подбор переводческих соответствий осуществлялся без учета особенностей реалий (непонятно, откуда на Черноморском побережье появился «аутентичный» океанский песок - authentic ocean sand), немотивировано употребление эквивалента relaxation вместо rest или vacation.

Текст 3 и его перевод иллюстрируют проблемы, связанные с составлением качественного исходного и переводного текстов, а также свидетельствуют о недооценке отельером такой важной составляющей имиджа гостиницы, как языковая привлекательность. Экономия на услугах переводчика и редактора при создании исходного текста и его переводе на иностранные языки приводит к потере будущей прибыли.

Сайт гостиницы является маркетинговым текстом, основная задача которого - привлечь новых клиентов. Выполнение данной задачи становится возможным только при условии следования грамотно выбранной стратегии перевода, знания стандартных формулировок и отсутствия в тексте различных языковых и речевых ошибок, приводящих к тому, что потенциальный гость может покинуть сайт отеля, не сочтя его достаточно понятным или читабельным и, следовательно, заслуживающим доверия.

\section{5}

Основная проблема XX в. в переводческой отрасли в целом и в туристической сфере в частности состоит в том, что количество людей, знающих иностранные языки, растет. 
Это, несомненно, положительный фактор, поскольку туристы имеют возможность знакомиться, общаться с представителями той страны, куда они приезжают на отдых, на их родном языке или как минимум используя «лингва франка» нашего времени - упрощенный английский язык. Однако при этом происходит обесценивание профессионального труда переводчика: каждый, знающий язык, считает, что он может переводить. Результатом такой деятельности становятся тексты, написанные на русском языке, которые по содержанию практически не искажают оригинальный текст, но в целом не являются высококлассным профессиональным переводом, так как при сохранении большей части когнитивной информации они утрачивают функционально-прагматическую информацию. Таким образом, и получатели, и отправители привыкают к низкому качеству текста.

Стратегия переводчика, работающего над переводом маркетинговых текстов, созданных для привлечения максимально возможного количества потенциальных гостей иного лингвосоциума, должна быть нацелена на создание такого текста, который будет восприниматься потенциальным покупателем не как перевод иноязычного текста, а как оригинальный текст, следовательно, становятся востребованными такие компетенции профессионального переводчика, как креативность и виртуозное владение идиомами языкового пространства. Переводной текст гостиничного сайта должен не только точно и адекватно оригиналу передавать содержание исходного текста, но и в доступной для гостей сайта форме демонстрировать преимущества гостиницы. В большинстве случаев переводческая стратегия для данного типа и жанра текста - порождение нового текста с определенными стилистическими маркерами и образными характеристиками, требующего изменения формы и структуры оригинального текста.

\section{ПРИМЕЧАНИЕ}

${ }^{1}$ Исследование выполнено при финансовой поддержке Российского фонда фундаментальных исследований (РФФИ) и Администрации Волгоградской области, проект № 17-14-34001 «Региональ- ный туризм как фактор формирования дискурса и технологии перевода: номинативные и коммуникативно-прагматические конвенции текстов брендинга» (Региональный конкурс «Волжские земли в истории и культуре России» 2017 - Волгоградская область).

\section{СПИСОК ЛИТЕРАТУРЫ}

Гуреева, А. A. PR-функция текста туристического брендинга: лингвистические средства как способ реализации / А. А. Гуреева // Брендинг как коммуникативная технология XXI века : материалы III Bсерос. науч.-практ. конф. (Санкт-Петербург, 13 марта 2017 г.). - СПб. : С.-Петерб. гос. экон. ун-т, 2017.-C. $128-131$.

Дорофеева, А. А. Туризм в исследованиях российских филологов / А. А. Дорофеева, А. А. Дорофеев // Языковой дискурс в социальной практике : сб. науч. тр. Междунар. науч.-практ. конф. (Тверь, 3-4 апр. 2015 г.). - Тверь : Твер. гос. ун-т, 2015. - C. 80-86.

Меньшикова, Е. Е. Лингвопрагматические особенности текстов туристической рекламы / Е. Е. Меньшикова // Современные исследования социальных проблем. - 2010. - № 2. - С. 98-99. - Электрон. текстовые дан. - Режим доступа: http://sisp.nkras.ru/eru/issues/2010/02/46.pdf (дата обращения: 15.05.2017). - Загл. с экрана.

Митягина, В. А. Коммуникативные действия в туристическом дискурсе / В. А. Митягина // Иностранные языки в высшей школе. - 2009. - № 4. C. $88-97$.

Новикова, Э. Ю. Туристический имидж глокального города: лингвопрагматическое измерение / Э. Ю. Новикова // Вестник Воронежского государственного университета. Серия: Лингвистика и межкультурная коммуникация. - 2015. - № 1. - С. 53-57.

Новожилова, А. А. Интернет-сайт отеля как значимый кластер туристического дискурса: лингвистический и транслатологический аспекты / А. А. Новожилова // Лингвистическая и транслатологическая логистика многоязычного туристического интернет-ресурса : коллектив. моногр. / под общ. ред. В. А. Митягиной. - Волгоград : Изд-во ВолГУ, 2016. - С. 81-103.

Новожилова, А. А. Стратегии перевода текстов туристического дискурса (на материале сайта отеля) / А. А. Новожилова // Современные исследования социальных проблем. - 2015. - № 8 (52). C. 138-149. - DOI: http://dx.doi.org/10.12731/22187405-2015-8-11.

Тарнаева, Л. П. Туристический дискурс: лингвопрагматические характеристики / Л. П. Тарнаева, В. В. Дацюк // Вестник Санкт-Петербургского 
университета. Серия 9. Филология. Востоковедение. Журналистика. - 2013. - № 3. - С. 229-235.

Austermühl, F. Training translators to localize / F. Austermühl. - Auckland : University of Auckland, 2015. $-340 \mathrm{p}$.

Dörnyei, Z. The effects of intercultural contact and tpurism on language attitudes and language leaarning motivation / Z. Dörnyei, K. Csizer // Journal of Language and Social Psychology. - 2005. - Vol. 24, iss. 4. - 327-357. - DOI: https://doi.org/10.1177/ $0261927 X 05281424$.

Gouadec, D. Le traducteur, la traduction et l'entreprise / D. Gouadec. - Paris :AFNOR, 1989. - 181 p.

Potočnik Topler, J. Language, discourse and communication in globalized tourism / J. Potočnik Topler // Literature, language and culture influenced by globalization. Vol. 7 / ed. by L. Shlossman. -Vienna : "East West" Association for Advances Studies and Higher Education GmbH, 2015. - P. 51-61.

Pym, A. Website localization / A. Pym // The Oxford Handbook of Translation Studies / ed. by K. Malmkjaer, K. Windle. - Oxford : Oxford University Press, 2011. - P. 410-424.

Sandrini, P. Website Localization and Translation / P. Sandrini. - 2005. - Electronic text data. - Mode of access: http://www.euroconferences.info/proceedings /2005_Proceedings/2005_Sandrini_Peter.pdf.

\section{REFERENCES}

Gureeva A.A. PR-funktsiya teksta turisticheskogo brendinga: lingvisticheskie sredstva kak sposob realizatsii [PR-Function of Tourism Branding Text: Linguistic Aspect]. Brending kak kommunikativnaya tekhnologiya XXI veka: materialy III Vseros. nauch.-prakt. konf. (SanktPeterburg, 1-3 marta 2017 g.) [Branding as a Communicative Technology of the 21 st Century. Proceedings of the 3rd All-Russian Scientific and Practical Conference (Saint Petersburg, March 1-3, 2017)]. Saint Petersburg, S.-Peterb. gos. ekon. un-t, 2017, pp. 128-131.

Dorofeeva A.A., Dorofeev A.A. Turizm v issledovaniyakh rossiyskikh filologov [Tourism as a Subject of Russian Philologists' Research]. Yazykovoy diskurs $v$ sotsialnoy praktike: sb. nauch. tr. Mezhdunar. nauch.-prakt. konf. (Tver, 3-4 apr. 2015 g.) [Language Discourse in the Social Practice. Collection of Scientific Works of Scientific and Practical Conference (Tver, April 3-4, 2015)]. Tver, Tverskoy gosudarstvennyy universitet, 2015, pp. 80-86.

Menshikova E.E. Lingvopragmaticheskie osobennosti tekstov turisticheskoy reklamy [LinguaPragmatic Peculiarities of the Tourism Advertisments]. Sovremennye issledovaniya sotsialnykh problem
[Modern Research of Social Problems], 2010, no. 2, pp. 98-99. URL: http://sisp.nkras.ru/e-ru/issues/2010/ 02/46.pdf. (accessed May, 15, 2017).

Mityagina V.A. Kommunikativnye deystviya $\mathrm{v}$ turisticheskom diskurse [Communicative Actions in the Tourism Discourse]. Inostrannye yazyki v vysshey shkole [Foreign Languages in Tertiary Education], 2009, no. 4, pp. 88-97.

Novikova E.Yu. Turisticheskiy imidzh glokalnogo goroda: lingvopragmaticheskoe izmerenie [Tourism Image of the "Glocal" City: Linguistic and Pragmatic Dimensions]. Vestnik Voronezhskogo gosudarstvennogo universiteta. Seriya: Lingvistika i mezhkul'turnaya kommunikatsiya [Proceedings of Voronezh State University. Series: Linguistics and intercultural communication], 2015, no. 1, pp. 53-57.

Novozhilova A.A. Internet-sayt otelya kakznachimyy klaster turisticheskogo diskursa: lingvisticheskiy i translatologicheskiy aspekty [Hotel Interne Site as an Important Cluster of Tourism Discourse: Linguistic and Translatological Aspects]. Mityagina V.A., ed. Lingvisticheskaya i translatologicheskaya logistika mnogoyazychnogo turisticheskogo internet-resursa: kollektiv. monogr. [Linguistic and Translatological Logistics of Multilingual Tourism Internet Resource. Collective Monograph]. Volgograd, Izd-vo VolGU, 2016. 233 p.

Novozhilova A.A. Strategii perevoda tekstov turisticheskogo diskursa (na materiale sayta otelya) [Translation Strategies for Tourism Discourse Texts (on the Example of a Hotel Website)]. Sovremennye issledovaniya sotsialnykh problem [Modern Research of Social Problems], 2015, no. 8 (52), pp. 138-149. DOI: http://dx.doi.org/10.12731/2218-7405-2015-8-11.

Tarnaeva L.P., Datsyuk V.V. Turisticheskiy diskurs: lingvopragmaticheskie kharakteristiki [Tourism Discourse: Lingvopragmatic Aspects]. Vestnik Sankt-Peterburgskogo universiteta. Seriya 9. Filologiya. Vostokovedenie. Zhurnalistika [Vestnik of Saint Petersburg State University. Series 9. Philology. Asian Studies. Journalism], 2013, no. 3, pp. 229-235.

Austermühl F. Training translators to localize. Auckland, University of Auckland, 2015.340 p.

Dörnyei Z., Csizer K. The effects of intercultural contact and tpurism on language attitudes and language learning motivation. Journal of Language and Social Psychology, 2005, vol. 24, iss. 4, pp. 327357. DOI: https://doi.org/10.1177/0261927X05281424

Gouadec D. Le traducteur, la traduction et l'entreprise [The Translator, the Translation and the Company]. Paris, AFNOR, 1989. 181 p.

Potočnik Topler J. Language, discourse and communication in globalized tourism. Shlossman L., ed. Literature, language and culture influenced by globalization. Vol. 7. Vienna, "East West" Association for Advances Studies and Higher Education $\mathrm{GmbH}$, 2015, pp. 51-61. 
Туристический дискурс: стратегии и проблемы перевода сайтов отелей

Pym A. Website localization. Malmkjaer K., Windle K. The Oxford Handbook of Translation Studies. Oxford, Oxford University Press, 2011, pp. 410-424.
Sandrini P. Website Localization and Translation. URL: http://www.euroconferences. info/ proceedings/2005_Proceedings/2005_Sandrini_ Peter.pdf.

\section{Information about the Authors}

Svetlana A. Korolkova, Candidate of Sciences (Pedagogy), Associate Professor, Department of Translation Theory and Practice, Volgograd State University, Prosp. Universitetsky, 100, 400062 Volgograd, Russian Federation, tipp@volsu.ru, http://orcid.org/0000-0003-2083-4101

Anna A. Novozhilova, Candidate of Sciences (Philology), Associate Professor, Department of Translation Theory and Practice, Volgograd State University, Prosp. Universitetsky, 100, 400062 Volgograd, Russian Federation, tipp@volsu.ru, http://orcid.org/0000-0001-7601-9048

Anastasia M. Sheyko, Candidate of Sciences (Philology), Assistant Professor, Department of Translation Theory and Practice, Volgograd State University, Prosp. Universitetsky, 100, 400062 Volgograd, Russian Federation, tipp@volsu.ru, http://orcid.org/0000-0002-8669-2292

\section{Информация об авторах}

Светлана Азадовна Королькова, кандидат педагогических наук, доцент кафедры теории и практики перевода, Волгоградский государственный университет, просп. Университетский, 100, 400062 г. Волгоград, Российская Федерация, tipp@volsu.ru, http://orcid.org/0000-0003-2083-4101

Анна Алексеевна Новожилова, кандидат филологических наук, доцент кафедры теории и практики перевода, Волгоградский государственный университет, просп. Университетский, 100, 400062 г. Волгоград, Российская Федерация, tipp@volsu.ru, http://orcid.org/0000-0001-7601-9048

Анастасия Михайловна Шейко, кандидат филологических наук, старший преподаватель кафедры теории и практики перевода, Волгоградский государственный университет, просп. Университетский, 100, 400062 г. Волгоград, Российская Федерация, tipp@volsu.ru, http://orcid.org/00000002-8669-2292 